\title{
Amonyak boran varlığında gözenekli stiren divinil benzen kopolimer küreciklerin optimum sentez koşullarının belirlenmesi
}

\author{
Gülay Özkan ${ }^{{ }^{*}}$, Göksel Özkan ${ }^{2}$, Esra İnce $^{2}$, Özge Bildi $^{3}$ \\ ${ }^{1}$ Ankara Üniversitesi, Kimya Mühendisliği Bölümü, 06100, Tandoğan, Ankara, Türkiye \\ ${ }^{2}$ Gazi Üniversitesi, Kimya Mühendisliği Bölümü, 06570, Maltepe, Ankara, Türkiye \\ ${ }^{3}$ Karatekin Üniversitesi, Kimya Mühendisliği Bölümü, 18200, Çankırı, Türkiye \\ Ö N E Ç I K A N L A R \\ - Optimum sentez koşullarının belirlenmesi \\ - $\quad$ Stiren divinil benzen kopolimeri sentezi \\ - Amonyak boran
}

Makale Bilgileri

Geliş: 13.01.2015

Kabul: 14.12 .2016

DOI:

10.17341/gazimmfd.300589

Anahtar Kelimeler:

Stiren divinil benzen

kopolimeri,

süspansiyon

polimerizasyonu,

yüzey alanı,

cevap yüzey yöntemi

\section{ÖZET}

$\mathrm{Bu}$ çalışmada, önemli endüstriyel polimerlerden stiren divinil benzen (SDVB) kopolimer küreciklerinin gözenekliliğini artırmak amacıyla amonyak boran varlığında sentezi ile optimum sentez koşulları araştırılmıştır. $\mathrm{Bu}$ amaç doğrultusunda başlatıcı olarak benzol peroksit, stabilizatör olarak polivinil alkol (PVA) ile sodyum hidroksit $(\mathrm{NaOH})$, organik çözücü olarak ikili toluen-hekzan karıșımı kullanılmış ve sentezler süspansiyon polimerizasyonu yöntemiyle yapılmıştır. Amonyak boran (AB) başlatıcı içine farklı miktarlarda karıștırılarak kullanılmıștır. Polimerizasyon tepkimesi azot atmosferinde, $80^{\circ} \mathrm{C}$ sicaklıkta ve atmosferik basınçta gerçekleştirilmiştir. Parametrik çalışmalar sonucu elde edilen kopolimer küreciklerinin yüzey alanı, gözenekliliği (BET analizleriyle), yapı tayini (Fourier transform infrared spektrometrisi, FTIR ile) ve sslak faz șișmesi gibi bazı karakteristik özellikleri belirlenmiștir. Sentezlenen kopolimerlerde AB'nin gözenek oluşumuna ve partikül boyut dağılımına katkı sağladığı, DVB yüzdesinin artmasıyla polimerizasyon verimi artarken küreciklerin şişme yüzdesinin azaldığı görülmüştür. Design Expert 8.0.7.1 (deneme sürümü) paket programı altındaki cevap yüzey yöntemi (CYY) kullanılarak merkezi kompozit tasarım yöntemine göre optimum sentez koşullarının \%90 DVB; 0,05 g amonyak boran; \%200 çözücü miktarında olduğu hesaplanmış ve bu koşullarda sentezlenen kopolimerlerin BET yüzey alanını $156 \mathrm{~m}^{2} / \mathrm{g}$ olarak ölçülmüştür. Asetonla yüzey modifikasyonu sonucu yüzey alanı $274 \mathrm{~m}^{2} / \mathrm{g}$ değerine arttırılmıştır.

\section{Determination of optimal synthesis conditions of porous styrene divinyl benzene copolymer beads in the presence of the ammonia borane}

\section{H I G H L I G H T S}

- Optimal synthesis conditions

- Synthesis of styrene divinylbenzene copolymer (SDVB)

- Ammonia borane

Article Info

Received: 13.01.2015

Accepted: 14.12 .2016

DOI

10.17341/gazimmfd.300589

Keywords:

Styrene-divinyl benzene, suspension polymerization, specific surface area, response surface method

\begin{abstract}
In this study, optimal synthesis conditions of important industrial polymer of porous styrene divinylbenzene copolymer (SDVB) beads are investigated in the presence of the ammonia borane in order to increase the porosity of the microspheres. In that purpose, benzoyl peroxide as radical initiator, polyvinyl alcohol (PVA) as stabilization, sodium hydroxide $(\mathrm{NaOH})$, toluene and hexane as organic diluent are used by suspension polymerization. In addition to initiator, different quantities of ammonia borane (AB) are used. In experimental studies, polymerization reaction is carried out under nitrogen atmosphere at $80^{\circ} \mathrm{C}$ and at atmospheric pressure. As results of parametric studies, copolymer beads are characterized by the surface area and porosity (BET), Fourier transform infrared spectrometry (FTIR), swelling analysis by wet method. It is seen that synthesized copolymers used $\mathrm{AB}$ contribute to pore generation and particular size distribution, as DVB percent increases, polymer efficiency increases but swelling percent decreases. By using RSM (Response Surface Method), according to central composite design method, optimum conditions are calculated as $90 \% \mathrm{DVB}$; $0,05 \mathrm{~g}$ ammonia borane; $200 \%$ solvent quantity and under these conditions, BET surface area of synthesized copolymers is found as $156 \mathrm{~m}^{2} / \mathrm{g}$. As a result of surface modification with acetone, surface area is increased to $274 \mathrm{~m}^{2} / \mathrm{g}$.
\end{abstract}

\footnotetext{
* Sorumlu Yazar/Corresponding author: gozkan@eng.ankara.edu.tr / Tel: + 903122033431
} 


\section{GİRIŞ̧ (INTRODUCTION)}

Polistirenin (PS) divinil benzen (DVB) ile çapraz bağlı gözenekli kopolimerleri 1950'li yıllarda keşfedilmiş ve genelde iyon değiştiriciler, gaz, sıvı ayırma prosesleri [1], katalitik uygulamalar, organik sentez gibi alanlarda yaygın kullanım alanı bulmuştur [2]. Stiren divinil benzen (SDVB) kopolimerleri; Amberlist, Amberlite, Dowex gibi isimlerle adlandırılan endüstriyel termoplastik ve reçinelerin temel yap1 malzemesini oluşturur. Bir veya daha fazla farklı monomerin ana monomere çapraz bağlanmasiyla elde edilen kopolimerler kullanım alanlarına göre jel veya reçine olarak da adlandırılmaktadırlar. Genellikle çapraz bağlayıcı oranını düşük olduğu (\%1-5) kopolimerler şişme özelliği gösteren jel tipi reçinelerdir ve yaygın olarak iyon değiştirici uygulamalarında kullanılırlar. Farklı olarak katalizör ve ayırma işlemlerinde kullanılan kopolimerlerde ise kalıcı gözeneklilik ve yüksek yüzey alanı elde etmek için çapraz bağlayıcı oranları daha yüksek seçilirken kullanılan seyreltici tip ve oranları da değişiklik gösterir. $\mathrm{Bu}$ tip uygulamalarda kopolimerlerin sentezlerinde; gözeneklilik (makro, mezo veya mikro), küre çapı, şişme gibi özelliklerin sağlanması için dikkatli bir tasarım ve tepkime sisteminin kontrolü gereklidir. Süspansiyon polimerizasyonu belli gözenekliliğe sahip 5-1000 $\mu \mathrm{m}$ çaplarında polimer kürecikler üretimi için en çok uygulanan proseslerden biridir [3]. Yapılan çalışmalarda polimerik jellerde çapraz bağ yoğunluğunun homojen olmadığı ortaya çıkmıştır. Jel oluşumunda serbest radikalik reaksiyon mekanizmasında jelleşme noktasından önce daha reaktif olan divinilbenzen (DVB) monomerinin ortamda fazla olmas1 gerektiği görülmüştür [3]. Düşük çapraz bağl1 polimerlerde şişme oranı fazla, gözenekliliği ve yüzey alanı $\left(0-50 \mathrm{~m}^{2} / \mathrm{g}\right)$ orta seviyelerde iken, mekanik dayanıklılı̆̆ 1 düşük ve yumuşak olduğu için kullanımı zordur. Yüksek çapraz bağlı polimerler sert ve dayanıklıdır, çözücülerde çok az şişer, gözenekliliği ve yüzey alanı önemli değişimler gösterebilir. A $\breve{g}$ yapıların sentez şartları ile gözenek özellikleri arasındaki ilişki pek çok araştırmacı tarafından çalışılmıştır. Yüksek gözenekliliğe ve yüzey alanına sahip küreciklerin sentezinde tepkime sıcaklığı, seyreltici cinsiyle bileşimi, seyreltici konsantrasyonu (seyreltme derecesi) ve çapraz bağlama derecesi gibi pek çok parametrenin önemli olduğu ve çapraz bağlayıcı oranının ile ilgili çalışmalar hala yapılmaktadır. Ayrıca sentez esnası veya sonrasında yapıya amin, boran gibi fonksiyonel grup ilave edilerek yüksek yüzey alanlı kopolimerlerin elde edilebildiği çalıșmalar da son zamanlarda özellikle gazların depolanabilmesi ve ayrılması uygulamaları için ilgi çekmeye başlamıştır [4]. Seyreltici cinsi de özellikle yüksek gözenekli ve alanlı malzemelerde önemli bir parametre olduğu görülmüştür. İyi bir seyreltici küçük gözenekli ve yüksek yüzey alanlı polimer kürecikleri verirken, kötü seyreltici büyük gözeneklilik verebilmektedir [5]. Bunun yanında polimerik jeller çeşitli çözücüler ile muameleye tabi tutularak da makro gözenek yapılarının geliştirilebildiği bilinmektedir [6]. Bu çalışmada, daha çok süper absorban, iyon değiştirici, seçici reçine, GPC (Gel Permission Column) kolon dolgu maddesi, katalizörler gibi çok geniş uygulama alanları olan, yüksek gözenekliliğe sahip SDVB kopolimer küreciklerinin değişik çapraz bağlayıcı monomer oranları ve ikili seyreltici yüzdelerinde süspansiyon polimerizasyon tekniği (serbest radikal mekanizması) ile sentezi gerçekleştirilmiştir. Sentezlenen küreciklerin yüzey alanı ve gözenekliliği (BED), FTIR analizleri, şişme özellikleri belirlenmiştir. Yüksek yüzey alanlı SDVB üretimi için sentez koşulları ile yüzey alanı arasında geçerli bir model ortaya koyulmuş ve optimum sentez koşulları hesaplanmıştır.

\section{DENEYSEL METOT (EXPERIMENTAL METHODS )}

Deneylerde stiren ve DVB'nin serbest radikalik polimerizasyonu Şekil 1'de verilen temel prosedüre göre Şekil 2'de verilen dört boyunlu cam balon reaktöründe gerçekleștirilmiștir. Reaktör dibinden ortama sürekli azot gazı gönderilerek $\left(30 \mathrm{~cm}^{3} / \mathrm{min}\right)$ tepkime sırasında oluşan radikallerin hava içinde ve çözücüde çözünmüş oksijen ile yok olmaları engellenmiş ve tepkime ortamının manyetik karıştırıcı ve mekanik karıştırıcı ile birlikte karışması sağlanmıştır.

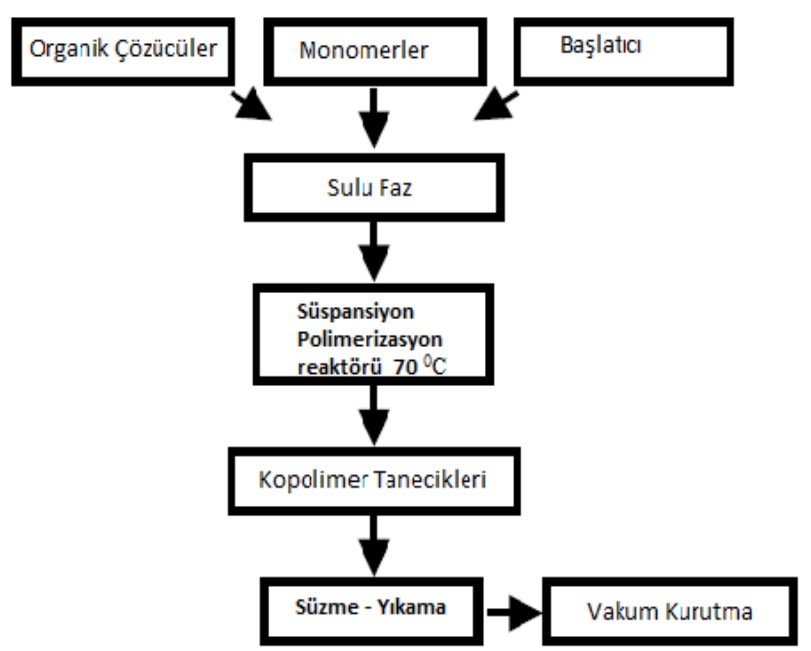

Şekil 1. SDVB kopolimerleri için sentez prosedürü (Synthesis procedure for SDVB copolymers)

Aynı zamanda buharlaşan çözücülerin geri kazanımı için (toluen + hekzan) bir geri soğutucu sisteme bağlanmıştır. Reaktöre saf su, stabilizatör, başlatıcı ve amonyak boran konularak homojen çözelti elde edilene kadar manyetik bir karıştırıcı ile karışımı sağlanmış ve belli bir ısı reaktöre verilmiştir. Sistem tepkimenin başlayacağı sıcaklığa $\left(70^{\circ} \mathrm{C}\right)$ geldiğinde reaktöre stiren, DVB ve organik çözücülerden oluşan karışım beslenerek polimerleşme tepkimesi başlatılmıştır. Tepkime sıcaklığ $180^{\circ} \mathrm{C}$ olacak şekilde sabitlenmiş 6 saat boyunca reaksiyon devam ettirilmiştir ve sonra soğumaya bırakılmıştır. Karıştırma durdurulduktan sonra çökeltinin üzerinde yüzen sıvı yavaşça boşaltılmıştır. Polimer kürecikleri birçok defa sıcak de iyonize su ile yıkanmış, süzülmüş ve vakum altında gece boyunca $60^{\circ} \mathrm{C}$ 
de kurutulmuştur. Deney sisteminde optimizasyon amaciyla deney parametrelerinden stiren/ DVB oranları çözücü hekzan ve toluen oranları ve amonyak boran miktarlarının alınması gereken alt ve üst sınır değerleri belirlenerek (Tablo 1) yapılması gereken parametrik deney planı Design Expert paket programıla belirlenmiş ilgili parametrelerle deneyler yapılmıştır. Yapılan deneylerde sıcaklık, karıştırma hızı, su miktarı dağıtıcı ajanlarının miktarı ve oranları sabit tutulmuştur.

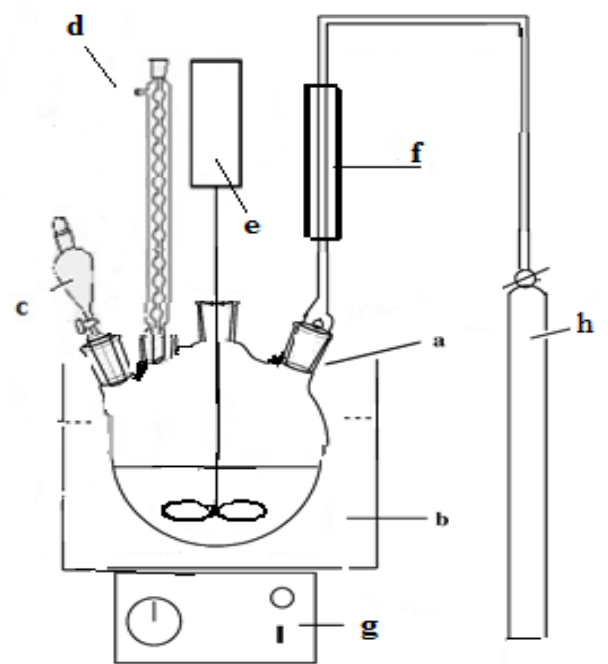

Şekil 2. Deney düzeneğinin şematik gösterimi (Schematic representation of the experimental setup) (a): $\mathrm{N}_{2}$ girişi, (b): yağ banyosu, (c): organik faz giriși, (d): geri soğutucu, (e): mekanik karıștırıcı, (f): rotametre, (g): magnetik karıştırıcılı sıcak plaka, (h): $\mathrm{N}_{2}$ gaz tüp

Tablo 1. Bağımsız-bağımlı değişkenler ve değişim aralıkları

(Independent and dependent variables and change interval)

\begin{tabular}{lll}
\hline $\begin{array}{l}\text { Bağımsız } \\
\text { Değişken }\end{array}$ & $\begin{array}{l}\text { Değişim } \\
\text { Aralığ } 1\end{array}$ & $\begin{array}{l}\text { Bağımlı } \\
\text { Değişken }\end{array}$ \\
\hline \% DVB & $30-90$ & BET yüzey alanı \\
$\begin{array}{l}\text { Amonyak Boran } \\
\text { miktarı }\end{array}$ & $0,05-0,1 \mathrm{~g}$ & $\mathrm{~m}^{2} / \mathrm{g}$ \\
\% Çözücü & $100-200$ & \\
\hline
\end{tabular}

\section{SONUÇLAR VE TARTIŞMALAR (RESULTS AND DISCUSSIONS)}

Son yıllarda, özellikle katalitik ve gaz fazı fiziksel işlemlerde (adsorpsiyon, membran vb. gibi) yüksek gözenekli polimerik yapılar yaygın uygulama alanları bulmaya başlamıştır. Yüksek yüzey alanlı ve gözenekli SDVB kopolimer küreciklerinin en uygun koşullarda sentezinin amaçlandığı bu çalışmada; DVB oranı, çözücü yüzdesi ile amonyak boranın miktarı bağımsız parametreler (faktör) olarak seçilmiştir. Düşük ve makro gözenekli kopolimer reçinelerin üretiminde genellikle tek bir çözücü (toluen, hekzan, heptan gibi ) bu çalışmada Azizollah vd. [7] benzer olarak daha yüksek yüzey elde edebilmek amacıyla ikili çözücü sistemi (toluen-hekzan) seçilmiştir.
Seçilen parametrelerin optimum değerlerini belirleyebilmek amacıyla merkezi kompozit tasarım kullanılmıştır. Daha sonra her bir SDVB sentezi için, belirlenen sınır değerleri Design Expert paket programına girilerek sistemin önerdiği deneyler yine önerilen koşullarda yapılmış ve ardından optimizasyon prosedürü uygulanmıştır [8]. Optimum koşullar belirlenirken Design-Expert 8.0.7.1 programı (deneme sürümü altındaki) Cevap-Yüzey Yöntemi (CYY) kullanılmıştır [9]. Bu programın kullanılmasının ana nedeni en az sayıda deney yaparak sistemin bütünleşik cevabını fonksiyon olarak görebilmek ve optimizasyonu gerçekleştirebilmektir. Program ile deneysel sonuçlar kullanılarak bir matematiksel model oluşturulmuş ve seçilen kriterlere göre optimum üretim koşullarını belirlemek amacıyla değerlendirilmiştir. Ayrıca Azizollah vd. literature ek olarak bağımlı değişken ile bağımsız değişkenler arasındaki anlamlı korelasyon üretmişlerdir [7]. $\mathrm{Bu}$ programın genel işleyişinde sistemden alınan cevap, cevabı etkileyen faktörlerin aynı anda değiştirilmesi ile sağlanmıştır. Böylece sistemden alınan cevaba, etkileyen faktörlerin iç etkisinin olup olmadığı da incelenmiştir.

Tablo 2'ye göre toplam 14 deney yapılmış ve her bir deneyde parametreler sistematik olarak değiştirilerek çıktı parametresi olarak BET yüzey alanları ve gözenekleri incelenmiştir. Numunelerin yüzey alanları ve ortalama gözenek çapları çok nokta analiz tekniğiyle ölçülmüştür. Ölçülen değerler Tablo 2'de verilmiştir. DVB içeriklerine göre örneklerin yüzey alanları toplu bir şekilde karşılaştırıldığında çapraz bağlayıcı miktarı (DVB) arttıkça yüzey alanı artmış, ortalama gözenek çapı sabit kalmıştır. Çözücüyle birlikte çapraz bağlayıcı miktarının artması yüzey alanını daha da artırmıştır. Ortalama gözenek çaplarında ise önemli bir artış olmamıştır [6]. Çapraz bağ oranının artmasının polimerlerde gözenekliliği artırdığı yönünde literatürde verilen sonuçlarla oldukça paralel olmuştur [7]. SDVB'nin literatürde reçine amaçlı kullanımında \%15'ten yüksek oranda kullanımının mezo gözeneklerde genişlemeyi engellediği ve çökmeler nedeniyle tercih edilmediği bilinmesine karşın bu çalışmada mikro-makro gözenekli yapılarında oluşturulması amaçlandığ 1 için yüksek DVB oranlarına çıkılmıştır. Ayrıca \% DVB içeren ticari SDVB'nin de BET yüzey alanı ölçülmüş ve Tablo 2'ye ilave olarak verilmiştir. Tablodan da görüldüğü gibi üretilen SDVB kopolimerlerinin yüzey alanları 10-215 m²/g olarak ölçülmüşken, ticari SDVB'nin (şişirme işlemi yapıılmamış) yüzey alanı $34 \mathrm{~m}^{2} / \mathrm{g}$ mertebesinde çıkmıştır. Bu sonuçta önemli ölçüde çapraz bağ oranına dolayısıyla DVB yüzdesine bağlanmıştır. Yine Tablo 2'den de görüldüğü gibi sabit çözücü (\%150) ve AB (0,08 g) değerlerinde \%30-90 arasındaki SDVB oranıyla elde edilen deneysel sonuçlarda yüzey alanını $48 \mathrm{~m}^{2} / \mathrm{g}$ 'dan $215 \mathrm{~m}^{2} /$ g'a çıkmıştır. Ortalama gözenek çapının ise $16^{\circ} \mathrm{A}$ değerine düşmesi mikro gözeneklerin arttığını desteklemiştir. AB'nin etkisi ise tam anlaşılamamıştır. AB'nin azalışı bazı deneylerde yüzey alanını artırmış bazılarında ise azaltmıştır. Yüksek yüzey alanlarına ulaşılan \%90 DVB oranında ve \%200 çözücü oranında AB'nin 0,05 g'dan 0,1'a artmasıyla yüzey alanında az artış gözlenirken 
Tablo 2. SDVB numuneleri için BET yüzey alanı ölçümleri, ortalama gözenek çapları ve asetonla muamele edilen SDVB numuneleri için BET yüzey alanı ölçümleri

(The BET surface area of SDVB samples, average pore diameter and the BET surface area of SDVB samples treated with acetone)

\begin{tabular}{|c|c|c|c|c|c|c|c|}
\hline & \multicolumn{3}{|c|}{ Bağımsız Değişkenler } & \multicolumn{4}{|c|}{$\begin{array}{l}\text { Bağımlı } \\
\text { Değişken }\end{array}$} \\
\hline Numune & $\begin{array}{l}\text { \%DVB } \\
(\mathrm{ml})\end{array}$ & $\begin{array}{l}\text { AB } \\
(g)\end{array}$ & $\begin{array}{l}\text { \%Çözücü } \\
\text { (hacimce) }\end{array}$ & $\begin{array}{l}\text { Yüzey } \\
\text { Alanı } \\
\left(\mathrm{m}^{2} / \mathrm{g}\right)\end{array}$ & $\begin{array}{l}\text { Ortalama } \\
\text { Gözenek } \\
\text { Çap1 } \\
\left(\mathrm{A}^{0}\right)\end{array}$ & $\begin{array}{l}\text { Asetonla } \\
\text { Y1kamadan } \\
\text { Sonra } \\
\text { Yüzey Alanı } \\
\left(\mathrm{m}^{2} / \mathrm{g}\right)\end{array}$ & $\begin{array}{l}\text { Yüzey } \\
\text { Alanı Artış } \\
\text { Yüzdesi } \\
(\%)\end{array}$ \\
\hline SDVB 8 & 90 & 0,10 & 200 & 115 & 24 & 235 & 104,35 \\
\hline SDVB 13 & 90 & 0,10 & 100 & 86 & 19 & 115 & 33,72 \\
\hline SDVB 21 & 90 & 0,08 & 150 & 215 & 16 & 271 & 26,05 \\
\hline SDVB 11 & 90 & 0,05 & 100 & 55 & 23 & 97 & 76,36 \\
\hline SDVB 12 & 90 & 0,05 & 200 & 109 & 23 & 93 & $-14,68$ \\
\hline SDVB 22 & 60 & 0,08 & 200 & 73 & 19 & 223 & 205,48 \\
\hline SDVB 23 & 60 & 0,08 & 100 & 16 & 19 & 48 & 200,00 \\
\hline SDVB 24 & 60 & 0,10 & 150 & 61 & 18 & 185 & 203,28 \\
\hline SDVB 25 & 60 & 0,05 & 150 & 112 & 19 & 149 & 33,04 \\
\hline SDVB 14 & 30 & 0,05 & 100 & 83 & 19 & 54 & $-34,94$ \\
\hline SDVB 15 & 30 & 0,05 & 200 & 75 & 19 & 34 & $-54,67$ \\
\hline SDVB 26 & 30 & 0,08 & 150 & 48 & 18 & 45 & $-6,25$ \\
\hline SDVB 17 & 30 & 0,10 & 200 & 74 & 19 & 54 & $-27,03$ \\
\hline SDVB 16 & 30 & 0,10 & 100 & 51 & 19 & 63 & 23,53 \\
\hline Ticari SDVB & 2 & - & - & 34 & - & - & - \\
\hline
\end{tabular}

$\left(109-115 \mathrm{~m}^{2} / \mathrm{g}\right)$ çözücü yüzdesi $\% 100$ de iken alan 55 $\mathrm{m}^{2} / \mathrm{g}$ 'dan $86 \mathrm{~m}^{2} / \mathrm{g}$ 'a artmıştır. Öte yandan $\% 60$ DVB ve $\% 150$ çözücü için $\mathrm{AB}$ miktarıyla alan $112 \mathrm{~m}^{2} / \mathrm{g}$ 'den 83 $\mathrm{m}^{2} / \mathrm{g}$ 'ye düşmüştür. Benzer durum \%30 DVB oranında da gözlenmiştir. Ancak deneylerde AB'nin ortalama gözenek çapına etki ettiği, $\mathrm{AB}$ oranı azaldıkça gözenek çapının büyüme eğiliminde olduğu gözlemlenmiştir. $\mathrm{AB}$ katılmasının ve diğer iki bağımsız parametrenin daha iyi anlaşılabilmesi için literatürde verilen sonuçların genellikle uygun bir çözelti (asidik veya bazik çözelti, aseton, metanol gibi) içerisinde şişirilip kurutulduktan sonra ölçüldüğü görülmüştür. Bu nedenle önce üretilen numuneler aseton ile yıkanmış ve kurutularak yüzey alanları ölçülmüştür. Bu amaçla sentezlenen SDVB numuneleri kaynama noktasında 12 saat boyunca aseton ile muamele edilmiş etüvde kurutulmuş sonra yüzey alanları ölçülmüsş ve Tablo 2 'de sonuçlar verilmiştir. Tablo 2'ye bakıldığında, genel olarak asetonla jelleştirme yüksek DVB oranlı SDVB numunelerinin yüzey alanlarını bir miktar daha artırırken, düşük DVB oranlı SDVB numunelerinin yüzey alanlarının bir miktar azalmasına sebep olmuştur. Literatürde polimerizasyonun jelleşme sırasında oluşan gözenekliliğin kararlı, reaksiyon sonuna doğru oluşan gözenekliliğin ise kararsız olduğu ve bu nedenle mikro gözenekliliğin çökebileceğinden bahsedilmektedir. \%30 DVB oranında bu durum gözlenmiş oysa $\% 60$ ve $\% 90$ DVB oranlarında tersine baskın oluşan mikro gözenekler olduğu için, bu gözeneklerin açılması veya kırılması söz konusu olduğu sonucuna varılmıştır. Sentezlenen stiren divinil benzen kopolimerlerinin şişme oranları [10] hesaplanmış ve sonuçları Şekil 3'de verilmiştir. Şekil 3 incelendiğinde genel olarak yüksek DVB oranında $\mathrm{AB}$ miktarı yüksekken çözücü yüzdesi arttığında șișme oranı büyük oranda artarken, AB miktarı azaldığında çözücü yüzdesi arttığında şişme yüzdesi tam tersi bir şekilde azalmıştır. Sonuçlar çözücü yüzdesinin artması ile artan eğilim literatürle uyumluluk göstermiş olup, azalma eğilimi $\mathrm{AB}$ ilavesine bağlanmıştır [11]. İlk defa denenen AB'nin gözenek oluşumunu artırıcı etki gösterdiği dolayısıyla yüksek $A B$ miktarlarında şişme oranını artmasına katkı sağladığı görülmüştür. Toluen ve hekzan ortamında 6 saat süreyle ve $80^{\circ} \mathrm{C}^{\text {' }}$ de sentezlenen stiren divinil benzen kopolimerlerinin elde edilen yıkanmış ve kurutulmuş polimer kütlesine oranlanmasıyla hesaplanan kopolimere dönüşüm yüzdeleri Şekil 4'de verilmiştir. Genel olarak değerlendirildiğinde AB'ın polimere dönüşüm verimini artırdığı, dolayısıyla boran kompleksi başlatıcı gibi reaksiyon hızını olumlu etkilediği şeklinde yorumlanmıştır.

Yüksek yüzey alanlı stiren divinil benzen kopolimer kürecikleri sentezi deneylerinde optimum koşullarının belirlenmesi için Design Expert 8.0.7.1 (deneme sürümü) paket programı altındaki cevap yüzey yöntemi (CYY) ve Tablo 2 deki veriler kullanılmıştır. Design Expert 8.0.7.1 paket programı yardımı ile gerçekleştirilen istatistiksel analizler sonucunda BET yüzey alanını tanımlayan modelin doğrusal (mean \& lineer) model olduğuna karar verilmiştir. Bunun sistem tarafindan seçilmesindeki etken $R^{2}$ (Adj RSquared) ve tahmin edilen $\mathrm{R}^{2}$ (Pred R-Squared) değerleri arasındaki farkın birbirine diğer modellere nazaran daha yakın olmasındandır. Paket program kullanılarak yapılan analizler sonucunda yüzey alanı için seçilen bağımlı parametreyi bağımsız parametrelere bağlayan matematiksel ifade (Eş. 1) elde edilmiştir. 


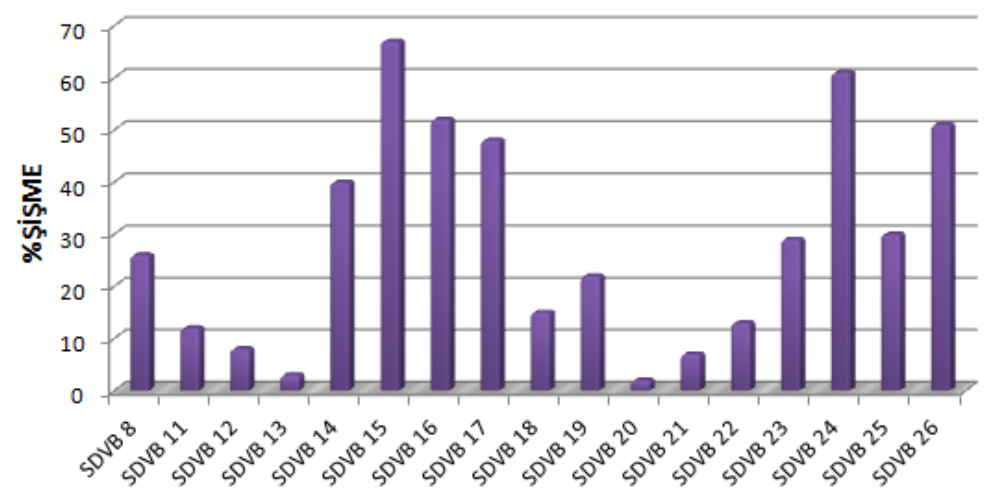

Şekil 3. \% Şişme oranı (Percentage of swelling ratio)

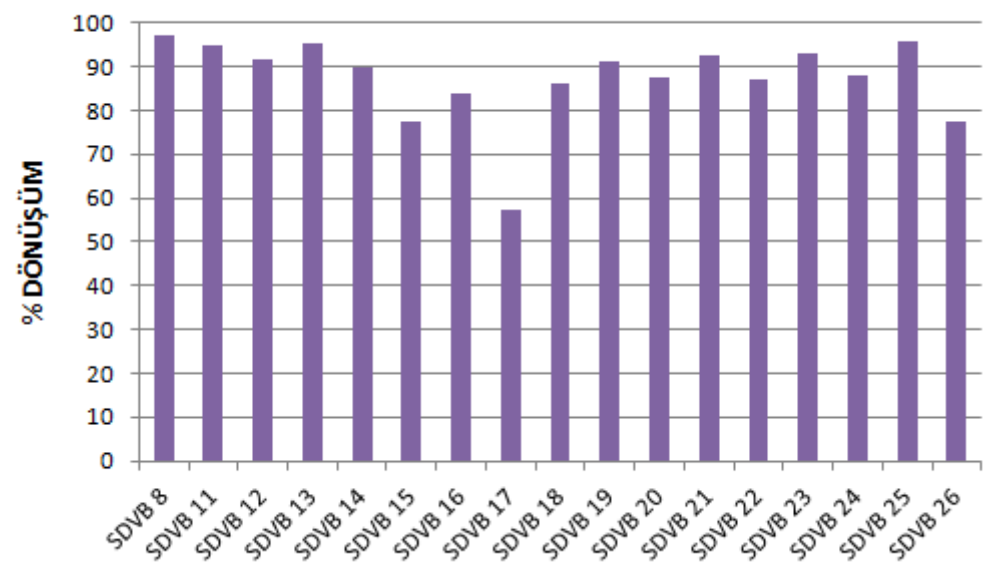

Şekil 4. \% Polimere dönüşümü (Percentage of polymer conversion)

BET Yüzey Alanı $=28.40 * \mathrm{X}_{\% \mathrm{DVB}}-1.20 * \mathrm{Y}_{\mathrm{AB}}+19.00 *$ $\mathrm{Z}_{\% \text { CÖZÜCÜ }}+12.88 * \mathrm{X}_{\% \text { DVB }} * \mathrm{Z}_{\% \text { CÖZÜCÜ }}+91.22 *\left(\mathrm{X}_{\% \mathrm{DVB}}\right)^{2}$ $+4.22 *\left(\mathrm{Z}_{\% \text { ÇÖZÜCÜ }}\right)^{2}$

Burada; $\mathrm{X}_{\% \mathrm{DVB}}$, DVB yüzdesi, $\mathrm{Y}_{\mathrm{AB}}$, amonyak boran

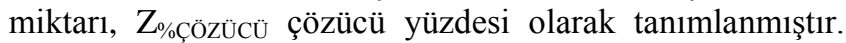
Şekil 5'de önerilen model ve deneysel olarak gözlenen yüzey alanı sonuçları verilmiştir. Grafik üzerindeki sistem tarafindan otomatik olarak belirlenen renk kutucuklarının maviden kırmızıya doğru dönüşmesi, yüzey alanının arttığını ifade etmektedir. Şekil 5 incelendiğinde BET yüzey alanının modelle arasındaki kısmen de olsa uyumluluk olduğu ve verilen modelin sistem parametreleri çerçevesinde uygun olarak kabul edilebileceğini göstermiştir. Özellikle yüksek yüzey alanında sapmalar göze çarpmaktadır. Stiren divinil benzen kopolimer kürecikleri sentezlendikten sonra Design Expert programı kullanılarak Tablo 2 verileri ve Eş. 1 kullanılarak ortalama doğrusal model yaklaşımı ile optimizasyon çalışmaları yapılmış ve Tablo 3 optimum yüzey alanını veren bağımsız parametreler elde edilmiştir. Şekil 6 incelendiğinde DVB yüzdesi ve çözücü yüzdesi arttığında yüzey alanı da artmıştır. Yüzey alanı sonuçları DVB yüzdesinin artması \%200 çözücü kullanılarak sentezlenen SDVB numuneleri,
\%100 çözücü kullanılarak sentezlenen SDVB numunelerine göre daha fazla arttırmıştır. \%90 DVB ve $0,10 \mathrm{~g} \mathrm{AB}$ içeren numuneler incelendiğinde çözücü yüzdesi arttığında yüzey alanı artmış; \%90 DVB ve 0,05 g AB içeren numuneler incelendiğinde ise yine çözücü yüzdesi arttığında yüzey alanı artmıştır. \%30 DVB ve 0,10 g AB içeren numuneler incelendiğinde çözücü yüzdesi arttığında yüzey alanı artarken \%30 DVB ve 0,05 g AB içeren numunelerde çözücü yüzdesi arttığında yüzey alanı azalmıştır. Yüksek DVB oranına sahip olan reçinelerde çapraz bağlanma yoğunluğu fazla olduğu için yüzey alanları yüksekken, düşük DVB oranına sahip olan reçinelerde çapraz bağlanma yoğunluğu düşük olduğu için yüzey alanlarının düşük çıkması literatürle uyum sağlamıştır.

Tablo 3. Optimum sentez koşulları (The optimum synthesis conditions)

\begin{tabular}{llll}
\hline $\begin{array}{l}\text { \%DVB, } \\
\mathrm{ml} / \mathrm{ml}\end{array}$ & $\begin{array}{l}\text { AB miktar1, } \\
\mathrm{g}\end{array}$ & $\begin{array}{l}\text { \%Çözücü, } \\
\mathrm{ml} / \mathrm{ml}\end{array}$ & $\begin{array}{l}\text { BET, } \\
\mathrm{m}^{2} / \mathrm{g}\end{array}$ \\
\hline 90,00 & 0,05 & 200,00 & 156,92 \\
\hline
\end{tabular}

Şekil 6'da ise optimizasyon sonucu üç parametre için yine program tarafindan oluşturulan dağılım (countour) eğrileri çizilmiştir. 

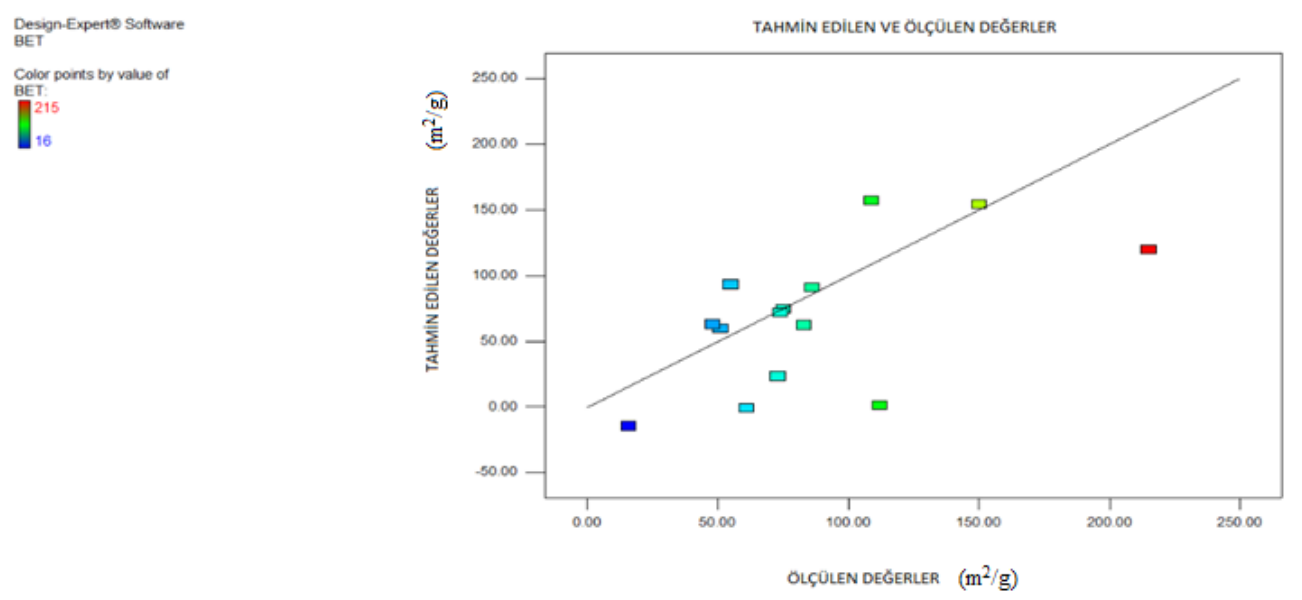

Şekil 5. SDVB kopolimerleri için deneysel olarak gözlenen (actual) ve modelden hesaplanan (predicted) BET yüzey alanı grafiği

(Surface area of SDVB copolymers for the experimentally observed (actual) and calculated by the model (predicted))

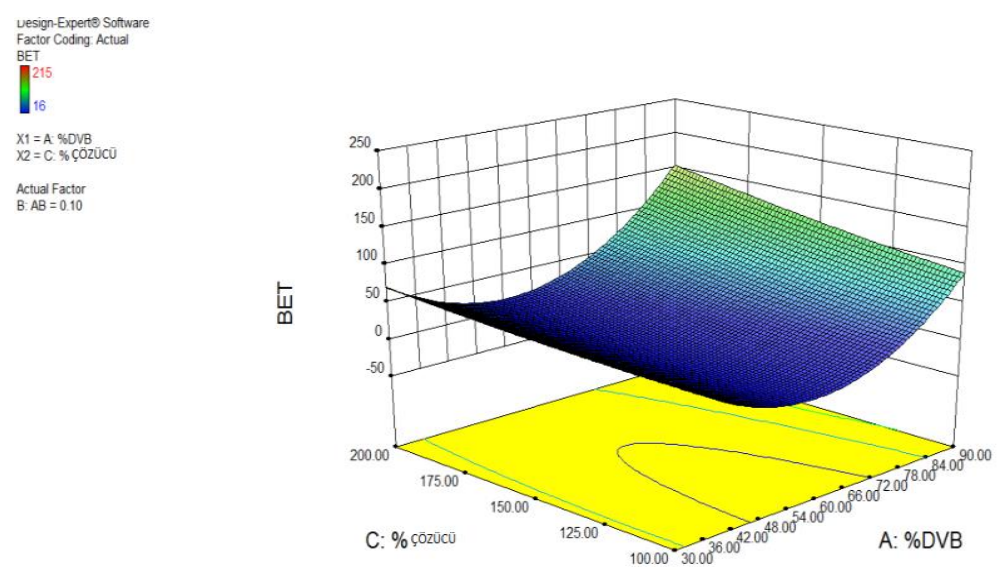

Şekil 6. Yüzey alanı dağılım eğrisi (Countour of SDVB)

\section{SONUÇLAR (CONCLUSIONS)}

Yapılan çalışmada, farklı DVB oranlarında, farklı çözücü yüzdelerinde ve amonyak boran katkılı SDVB kopolimerleri sentezlenmiş ve bazı karakteristik özellikleri belirlenmiştir. Sentez ağının polimer etkileşimlerinin kapsamı (çözücü + monomer), çapraz bağlayıcının ve çözücünün miktarları gibi bağımsız değişkenleri değiştirilerek çapraz bağlanma prosesi boyunca çeşitli gözenekli yapıların elde edilebildiği gösterilmiştir. Design Expert 8.0.7.1 (deneme sürümü) paket programı altındaki cevap yüzey yöntemine (CYY) kullanılarak merkezi deneysel tasarım yöntemine göre \% DVB, amonyak boran miktarı, \% çözücü bağımsız değişken, BET yüzey alanı sonuçları ise bağımlı değişken alınarak bağımlı değişken ile bağımsız değişken arasında korelasyon bulunmuştur. $\mathrm{Bu}$ korelasyondan yararlanılarak maksimum yüzey alanı değerini verecek işletim parametreleri belirlenmiştir. Optimum koşullar \%90 DVB; 0,05 g amonyak boran; \%200 çözücü miktarında BET yüzey alanı sonucu $156.919 \mathrm{~m}^{2} / \mathrm{g}$ olarak bulunmuştur. Yapılan optimizasyona ait dağılım grafiklerine bakıldığında amonyak boran miktarının yüzey alanı sonuçlarına etkisi ihmal edilebilir düzeyde olduğu, DVB ve çözücü yüzdelerinin ise artmasıyla yüzey alanının arttığı bulunmuştur. Diğer taraftan sentezlenen SDVB numunelerinin asetonla yıkanmasının yüzey alanı üzerine etkisi de araştırılmıştır. Asetonla yıkamanın yüksek DVB oranlarındaki SDVB kopolimerlerinin gözeneklerinde kalan kalıntıları temizleyerek yüzey alanlarını bir miktar daha arttırdığ 1 belirlenmiştir. Düşük DVB oranlarında ise tam tersi gözlenmiştir. Okay, O [6] ve Azizollah vd. [7] paralel olarak bu durumun sebebi polimerizasyonun jelleşme esnasında oluşan gözeneklerin kararlı yapıda olmasından ve reaksiyon sonuna doğru oluşan gözeneklerin ise kararsız yapıda olmasından kaynaklandığ SDVB numunelerinin yaş yöntem ile şişme tayinleri yapılmıştır ve DVB yüzdesi düşük olan numunelerin \% şişmeleri daha yüksek, DVB yüzdesi yüksek olan 
numunelerin ise çok daha düşük olduğu görülmüştür. $\mathrm{Bu}$ sonuç Okay, O [6] ve Al-Sabti vd [11] verilen düşük çapraz bağ yapılı polimerlerde (\%2-15 DVB) şişme oranlarının yüksek elde edilmesi sonucuyla uyumluluğu göstermiştir. Yüksek DVB oranında yüksek çapraz bağ yapılı kopolimerlerin çok az şişmeleri özellikle gaz karışımlarının ayrilmasında, gaz adsorpsiyonunda kullanımlarını ve katalitik uygulamalarda tepkimeye yüzeyleri ile katılmalarını mümkün kılmaktadır. Şişme oranını düşmesine karşın gözenekliliklerinin artması bu tip uygulamalarda kullanılabilirlik olasılığını artırmıştır. Üretilen SDVB kopolimerlerinin ayrica sentez verimleri de hesaplanmış ve DVB yüzdesi arttıkça polimer veriminin arttığı, DVB yüzdesi azaldığında ise polimer veriminin azaldığ́1 görülmüştür. Sentezlenen kopolimerlerin yap1 tayinleri FTIR spektroskopisi kullanılarak yapılmış ve FTIR analizleri sonucu sentezlenen kopolimerlerin yapısında borlu bileşiğe rastlanmamıştır. Yapılan araştırmalar ile amonyak boranın başlatıcı olarak etki gösterdiği belirlenmiştir.

\section{KAYNAKLAR (REFERENCES)}

1. Salemi A., Vosough M., Mazlumi E., Determination of UV - filter Compounds in highly contamina ted river water by HPLC-DAD: A comparative study on extraction efficiency and applicability of different solid phase extraction sorbents, J. Liq. Chromatogr. Related Technol., 35 (15), 2113-2114, 2012.

2. Castiglioni G.L., Cuellar J., Rodrigo R., Costa J.A.V., Alegre R.A. Application of Poly(styrene-codivinylbenzene) Macro porous Micro particles as a Catalyst Support in the Enzymatic Synthesis of Biodiesel, J. Polym. Environ., 24 (3), 264-273, 2016.

3. Okay O., Erbay E., Pore Memory of Macro porous Styrene-Divinyle Benzene Copolymers, J. Appl. Polym. Sci., 71, 1055-1062, 1998.
4. Svec F., Fréchet J.M.J., New designs of macroporous polymers and supports: From separation to biocatalysts, Science, 273, 205-2011, 1996.

5. Badyal J.P., Cameron A.M., Cameron N.R., Oates L.J., Qye G., Steel G.P., Davis B.G., Coe D.M., Cox R.A., Comparison of the effect of pore architecture and bead size on the extent of plasma chemical amine functionalization of poly(styrene-codivinylbenzene) permanently porous resins, Polymer, 45 (7), 21852192, 2004.

6. Okay O., Macroporous copolymer networks, Prog. Polym. Sci, 25, 711-779, 2000.

7. Azizollah N., Mohammad H., Mahmoud P., Correlations for Prediction of Specific Surface Area and Bulk and Apparent Densities of Porous StyreneDivinylbenzene Copolymers, J. Appl. Polym. Sci, 120, 1942-1949, 2011.

8. Özkan G., Akin B.A., Özkan G., The prediction of chemical oxygen demand (COD) or suspended solid (SS) removal using statistical methods and the artifical neural network in the sugar industrial wastewaters removal using statistical methods and the artifical neural network in the sugar industrial wastewaters, ARPN Journal of Engineering and Applied Sciences, 8, 978-983, 2013.

9. Ersan M., Acikel U., Optimization of acid phosphatase production and $\mathrm{Zn}$ (II) bioaccumulation by $\mathrm{R}$. delemar using response surface method, Journal of the Faculty of Engineering and Architecture of Gazi University 29 (2), 321-329,2014.

10. Ínce Özsoy E., Süspansiyon polimerizasyonu ile gözenekli stiren divinil benzen kopolimeri sentezi ve karakterizasyonu, Yüksek Lisans Tezi, Gazi Üniversitesi, Fen Bilimleri Enstitüsü, Ankara, 2014.

11. Al-Sabti M.D., Jawad J.K., Jacob W.F., Preparation of Macroporous Styrene-Divinylbenzene Copolymers, Eng.\& Technology, 25 (9),1041-1045, 2007. 
